\title{
Survey about the most Important CCPs of the Agricultural Certification Systems in Greece
}

\author{
Aristidis KONSTANTAS ${ }^{*}$, Dimitrios BILALIS ${ }^{1}$, Andreas KARAMANOS ${ }^{1}$, Nikolaos MPEOPOYLOS ${ }^{2}$ \\ ${ }^{1}$ Laboratory of Agronomy, Faculty of Crop Science, Agricultural University of Athens \\ ${ }^{2}$ Laboratory of Agricultural Extension, Agricultural Systems \& Rural Sociology, Agricultural University \\ of Athens, 75 Iera Odos str., GR 11855, Athens, Greece \\ *)corresponding author, e-mail: konar1979@yahoo.gr
}

BulletinUASVM Horticulture 72(2) / 2015

Print ISSN 1843-5254, Electronic ISSN 1843-5394

DOI:10.15835/buasvmcn-hort:11396

\begin{abstract}
Aim of the research was to record the Critical Control Points (CCPs) between the three agricultural certification systems: Organic Agriculture (OA), Integrated Management (IM) and Conventional Agriculture (CA). For the collection of the information, non-structured and in-depth interviews, as well as closed-ended questionnaires were used. A total of 25 people from various fields, always related to agriculture and particularly to certification, attended the interviews. Among those who participated in the interviews were academics, directors of certification organisations and cooperatives, journalists and others. Correspondingly, the sample of persons who completed the questionnaires included people involved in the agricultural sector (eg. producers, processors etc.), constituted of a representative sample of the research target group. Concluding, it was found that in Greece the most important CCPs of the three agricultural certification systems were: a) the subsidy in OA production, b) the pricing of IM products and c) the lack of state control in CA.
\end{abstract}

Keywords: Conventional Agriculture, CCP, Greece, Integrated Management, Organic Agriculture.

\section{INTRODUCTION}

In recent years, the need for consumption of agricultural products distinguished for their safety and quality is particularly intense. Consumers require, from everyone involved in the food chain, the application of high quality standards in order to ensure safety, hygiene and wholesomeness of produced agricultural products. (Mpeopoulos, 1999)

The EU according to the last amendment of the Common Agricultural Policy (CAP), places special emphasis on meeting the expectations of consumers regarding the quality and safety of products, in animal welfare and environmental protection, while now encourages farmers to produce high quality agricultural products, emphasizing the satisfaction of consumer expectations and following agricultural practices that respect the environment and protect the agro ecosystem. (Mpeopoulos, 1999)
The implementation of quality systems, which are inextricably linked with science, research, market needs, environmentally practices and consumer needs, might be able to satisfy the dictates of the new era (Kaltsis \& Chin, 2005). Moreover, the growing concerns about the environmental, economic and social effects of conventional chemical-dependent agriculture, have led many farmers and consumers in developing alternative practices and systems that will make agriculture more sustainable (Reganold, 1995), such as Organic Agriculture (OA) and Integrated Management (IM).

\section{AIMS AND OBDJECTIVES}

In this survey three different agricultural methods were examined:

Organic Agriculture (OA): According to IFOAM (2005), OA consists of a production system that sustains the health of soils, ecosystems 
and people. It relies on ecological processes, biodiversity and cycles adapted to local conditions rather than the use of inputs with adverse effects. $\mathrm{OA}$ combines tradition, innovation and science to benefit the shared environment and promote fair relationships and a good quality of life for all involved.

Integrated Management (IM): According to EISA (2012), IM consists of a rational management of the whole farm approach, which combines the ecological care of a diverse and healthy environment to agriculture financial requirements in order to ensure the continuous production of healthy and affordable food.

Conventional Agriculture (CA): CA is an intensive form of agriculture which applies high input systems for high performances. (Pacini et al., 2003)

Although numerous studies have examined the CCPs of the three agricultural certification systems alone, very few have gathered and recorded the information from all three in one study.

\section{MATERIALS AND METHODS}

For the collection of the information, nonstructured and in-depth interviews as well as closed-ended questionnaires were used. A total of 25 people from various fields, always related to agriculture and particularly to certification, attended the interviews. Among those who participated in the interviews were academics, directors of certification organizations and cooperatives, journalists and others. Correspondingly, the sample of persons who completed the questionnaires included people involved in the agricultural sector (eg. producers, processors etc.), constituted of a representative sample of our research target group. All the persons participated in both the interviews and questionnaires were chosen because of their long experience in the agricultural area and especially in the agricultural certification. It should also be noted, that the selection of the questionnaires sample was based on the theory of probability, meaning that all members of the population have an equal chance to be selected, and more specifically on the theory of random sampling.

The questions that were used during the interviews were open, and more specifically the participants were asked for the: a) relationship and differences of $\mathrm{OA}, \mathrm{IM}$ and $\mathrm{CA}, \mathrm{b}$ ) problems/critical control points of OA, IM and CA, c) solutions to the aforementioned problems/critical control points, d) evaluation of the certification schemes and e) future of the three systems.

Afterwards, the interviews information were categorised, and were used during the creation of the questionnaires. The steps which were followed for the finalisation, gathering and analysis of the questionnaires, can be summarised at the following: a) structure of the questionnaire, taking into consideration the replies of the interviews, b) selection of the target groups that will participate in questionnaires' survey, c) completion of the questionnaires, d) electronically recording of the responses and e) statistical analysis of the answers.

For the statistical analysis of both the interviews' and questionnaires' answers, the response rate was used and the answers were categorised from lower to upper percentage. In order to achieve commonly accepted CCPs between the answers recorded from the questionnaires and responses to the interviews' questions, limits on the percentages of the positive responses were delimited. More specifically, after selecting the common answers given by participants in interviews and questionnaires, three percentage limits were raised: a) $<50 \%$, b) $50 \%-70 \%$ and c) $>$ $70 \%$. This procedure was followed separately for each of the three certification systems.

\section{RESULTS AND DISCUSSIONS}

At the first percentage limit $(<50 \%)$ of $\mathrm{OA}$ results, common answers were recorded, both in interviews and questionnaires, namely: a) lack of quantity certificate, b) lack of producers and geotechnical's education, c) lack of proper visibility and promotion of OA products from the state, d) bureaucracy, e) existence of separate pricing for OA products, f) production of organic products mainly for the subsidy and g) lack of organized distribution network of organic products. These results are confirmed by the studies of Sarapuu et al. (2014), Sanders et al. (2014) and the IvanovaPeneva (2014), who found respectively CCPs, in the Bulgarian OA fields.

After the final filtering of the common answers, at the third limit ( $>70 \%)$, it was found "subsidy" to be the most important of the common CCPs of OA. Relevant results, were mentioned both in Theocharopoulos et al. (2012) research on the 
socio-economic approach of the three farming systems in Greece, and Tzouramani et al. (2008), which considers that the $\mathrm{OA}$ in Greece can be profitable only if it is subsidized. Specifically, the investigation of Theocharopoulos et al. (2012) demonstrated that in case that organic farmers in Greece do not receive a subsidy from the state, they will experience a loss. As noted by Alexopoulos et al. (2010) one of the reasons that a large percentage of Greek organic farmers would change to CA is the decoupling of state subsidies. Similar results were also found by Fairweather and Campell (1996) research, based on which a high proportion of organic farmers in New Zealand would change conventional crops if the state subsidy was stopped; by Lapple (2010) where the decoupling of subsidy from OA in Ireland led many organic farmers in the CA; and by Darnholf et al. (2005) whose research showed that the State aid (subsidy) is among the most important factors for the farmers in order to get involved in OA or even re-conservation. Similarly, the Bruckmeier et al. (1994) observed that in Germany the producers turn to OA driven mainly by economic reasons and less by environmental factors, which also appears in our research where main CCP for OA constitutes the subsidies, which lead to a greater economic benefit.

On the other hand, the common answers between interviews and questionnaires concerning the CCPs of IM at the first level $(<50 \%)$, were summarised at the following: a) bureaucracy, b) lack of education of producers and agronomists, c) IM products price, d) lack of proper promotion of the IM products and e) lack of IM product's "identity".

By filtering, for the third time $(>70 \%)$, the common results of IM it was found that the most important CCP, was "IM product's price". As mentioned by Swezy et al. (2007) in his research, the difference between the final price of the IM products and the high cost of their production is not large enough to push producers to convert their conventional or organic production to IM. These results are reinforced by Theocharopoulos et al. (2012), who states in his research that, due to the almost non-existent state subsidy for IM crops, the profit compared with subsidized conventional crops profit is almost zero (2.5\%). Also, the lack of discrete pricing for IM products, as opposed in
OA products, consists of a major limiting factor for producers to get involved with IM.

Finally, the common answers of CA's CCPs at the first level $(<50 \%)$ were: a) lack of education of producers and agronomists, b) lack of state control, c) lack of proper abroad promotion and d) fragmentation of land holdings. The final filtering $(>70 \%)$ led to the most important CCP of CA, which was "lack of state control".

\section{CONCLUSION}

Concluding, during the survey it was found that in Greece the most important CCPs of the three agricultural certification systems were: a) the subsidy in OA production, b) the pricing of IM products and c) the lack of state control in CA. The results of this survey can be the first step towards a wider research, where the CCPs of the three agricultural certification systems, will be compared and statistically analysed, using correlations and crosstabs.

\section{REFERENCES}

1. Alexopoulos G, Koutsouris A, Tzouramani I (2010). Should I stay or should I go? Factors affecting farmers' decisions to convert to organic farming or abandon it. Building sustainable rural future: The added value of systems approaches in times of change and uncertainty, $9^{\text {th }}$ European IFSA Symposium), Vienna, 4-7 July 2010.

2. Bruckmeier K, Grund H, Symes D, Jansen AJ (1994). Perspectives for environmentally sound agriculture in east Germany. Agricultural Restructuring and Rural Change in Europe. 37: 180-194.

3. Darnhofer I, Schneeberger N, Freyer B (2005). Converting or not converting to organic farming in Austria: Farmer types and their rationale. Agriculture and Human Values 22 (1): pp 39-52.

4. EISA (2012). European Integrated Farming Framework: A European Definition and Characterisation of Integrated Farming (IF) as Guideline for Sustainable Development of Agriculture.

5. Fairweather JR, Campell H (1996). The decision making of organic and conventional agricultural producers. Agribusiness and Economics. 233: pp 263-278.

6. IFOAM (2008). Available at: http://www.ifoam.bio/en/ organic-landmarks/definition-organic-agriculture (last accessed at 17/07/2015).

7. Ivanova-Peneva S (2014). Swot analysis of organic market in Bulgaria. Proceedings of the $4^{\text {th }}$ ISOFAR Scientific Conference - Building Organic Bridges, Turkey, Vol.1: pp 97-100.

8. Kaltsis I, Tsinas D (2005). Quality \& Certification primary production systems (in accordance with the principles of good agricultural practice and integrated 
crop management). New technologies in agricultural production and rural development, TEE, 13-15 May, 2005.

9. Lapple D (2010). Adoption and abandonment of organic farming: An empirical investigation of the Irish drystock sector. Journal of Agricultural Economics, Vol. 61, Issue 3, pp 697-714.

10. Mpeopoulos N (1999). An ecological history of rural areas.

11. Pacini C, Wossink A, Giesen G, Vazzana C, Huirne R (2003). Evaluation of sustainability og organic, integrated and conventional farming systems: a farm and field - scale analysis. Agriculture, Ecosystems and Environment 95: pp 273-288.

12. Reganold JP (1995). Soil Quality \& Profitability of Biodynamic \& Conventional Farming Systems. American Journal of Alternative Agriculture 10: pp 36-45.

13. Sanders J, Hamm U, Kuhnert H, Nieberg H, Strohm R (2014). Reversion of organic farms to conventional farming in Germany. Proceedings of the $4^{\text {th }}$ ISOFAR Scientific Conference - Building Organic Bridges, Turkey, Vol.2: pp 439-440.

14. Sarapuu K, Pehme S, Peetsmann E, Matt D (2014). The challenges organic food processors meet at small emerging market - Estonian case. Proceedings of the $4^{\text {th }}$ ISOFAR Scientific Conference - Building Organic Bridges, Turkey, Vol.1: pp 223-225.

15. Swezey SL,Goldman P, Bryer J, Nieto D (2007). Six-year comparison between organic, IPM and conventional cotton production systems in the Northern San Joaquin Valley. California. Renewable Agriculture and Food Systems 22(1): pp 30-40.

16. Theocharopoulos A, Aggelopoulos S, Papanagiotou P, Melfou K, Papanagiotou E (2012). Sustainable Farming Systems vs Conventional Agriculture: A Socioeconomic Approach. Sustainable Development - Education, Business and Management - Architecture and Building Construction - Agriculture and Food Security, Edited by Prof. Chaouki Ghenai, InTech: pp 249-272.

17. Tzouramani E, Liontakis A, Sintori A, Alexopoulos G (2008). Evaluation of economic incentives for organic farms: The case of organic cherry production. $10^{\text {th }}$ Greek Conference of Greek Society of Agricultural Economics, Thessaloniki (in Greek). 